University of New Hampshire

University of New Hampshire Scholars' Repository

5-14-2009

\title{
Working Together: A Literature Review of Campus Information Technology Partnerships
}

Eleta Exline

University of New Hampshire - Main Campus, eleta.exline@unh.edu

Follow this and additional works at: https://scholars.unh.edu/library_pub

Part of the Archival Science Commons, and the Science and Technology Studies Commons

\section{Recommended Citation}

Exline, Eleta. "Working Together: A Literature Review of Campus Information Technology Partnerships." Journal of Archival Organization 7, no. 1-2 (2009): 16-23.

This Article is brought to you for free and open access by the University Library at University of New Hampshire Scholars' Repository. It has been accepted for inclusion in University Library Scholarship by an authorized administrator of University of New Hampshire Scholars' Repository. For more information, please contact Scholarly.Communication@unh.edu. 


\title{
Working Together: A Literature Review of Campus Information Technology Partnerships
}

\author{
ELETA EXLINE \\ University of New Hampshire, Durham, New Hampshire, USA
}

This article reviews the recent literature about the essential but often uneasy alliances made between content experts (archivists and librarians) and technology experts. Differing professional cultures, misunderstandings of one another, limited abilities to envision change, and lack of support from top-level administrators are the most often cited reasons for the persistent difficulty in working together. Failure to collaborate may result in the marginalization or exclusion of content experts from projects where their professsional skills are most needed. In spite of these problems, successful models for working together do exist. True collaborations are mutually beneficial, open opportunities for continuing relationships, and involve complex interpersonal connections. They are based on trust, mutual understanding, and respect for one another's skills and respective professions.

KEYWORDS information technology, collaboration, partnerships, literature review

\section{INTRODUCTION}

During the New England Archivists Fall 2007 meeting "Dialogues: New Directions for College, University, and Schools Archives," I facilitated a discussion session titled "Working Together: Campus Digital Partnerships." The plan was to share experiences with building collaborative partnerships among college and university archivists, academic departments, and campus information technology (IT) departments in collecting, providing access to, and preserving digital content. While the discussion was wide-ranging

Address correspondence to Eleta Exline, MS LIS, Digital Collections Librarian, The University Library, University of New Hampshire, Durham, NH 03824. E-mail: eleta.exline@unh.edu 
and covered the challenges of collecting records and publications from administrative and academic departments, the art of negotiating informal and formal agreements for records retention, and the difficulties of educating departments about creating preservable digital documents, the most memorable points focused on a topic both narrower and more general - the essential, but uneasy alliances made between content experts (archivists and librarians) and technology experts.

Beginning in 1994 the Coalition for Networked Information (CNI) hosted a series of "Working Together" workshops similarly titled to our discussion session designed to foster collaborations between content experts and technology experts. After the 1998 event "Working Together: A Workshop for Archivists, Records Managers, and Information Technologists," CNI director Joan Lippincott identified the primary concerns of archivists expressed in that meeting as dealing with the management, policy, and legal ramifications of new electronic records formats. Collaboration with IT professionals is a necessary step in addressing at least some of these concerns. ${ }^{1}$ In the interveneing years the introduction of more electronic formats, delivery systems, and metadata schemes into archives and libraries has created opportunities for content experts to acquire more technological skills, yet these professionals still cannot supply all of the support required for a fully fledged electronic records program, digital library, or institutional repository. Collaboration with the information architects, programmers, Web designers, systems administrators, and database administrators of the IT sector remains essential to the work of archivists and librarians alike, but according to our session participants, these collaborations can be poorly conceived, awkwardly executed, or do not take place at all. This failure to work well together results in unrealized potential: images, texts, and finding aids remain locked in paper formats or posted on difficult to manage Web sites; electronic records disappear before they can be collected; institutional repositories languish; and archivists and librarians become frustrated in fulfilling their missions to preserve and provide access to our collective cultural heritage.

In this article I will attempt to assess and summarize our current understanding of the problems underlying collaborations between academic libraries and archives and campus IT departments through a review of the recent professional literature, keeping two key questions in mind: What are the barriers to collaboration between content experts and technology experts in academic institutions? What strategies, techniques, and models for working can be used to break these barriers down?

\section{THE LITERATURE}

The reviewed literature includes articles published in professional archives, library, and education journals over the past ten years, or since 1998. 
Subjects include partnerships, collaboration, and cooperation between content experts and technology experts, including obstacles to collaboration and models for working together successfully in academic settings. In her discussion of the foundations of the "Working Together" work shop series, Lippincott defines collaboration as being different from simply contracting work from another department. Instead, it is a joint effort based on mutual goals where the participants each bring skills and resources. Early workshop participants identified territoriality, physical distances (being housed in separate locations on campus), differences in professional culture, lack of respect for one another's professions, and a general failure to recognize the benefits of working together as key barriers to collaboration at their institutions. Furthermore, they identified the elements of a successful collaboration as including long-term commitment to working together, shared risks and benefits, and participation in decision making on both sides.

In 1999 Meri Beth Lavagnino interviewed top-level administrators of library and IT departments from several university campuses. Both groups envisioned increasingly close collaboration between library and IT staff as the only possible solution to the blurring of roles taking place between the units and the overall lack of space and financial resources facing both. They agreed unanimously that organizational or managerial structure mattered far less than mutual trust, respect, and understanding in the forging of successful, synergistic partnerships. ${ }^{3}$

Initially composed of four technologists and three librarians, Colgate University's Collaboration for Enhanced Learning (CEL) is a cooperative effort between IT and the library to support teaching and learning on campus. Mary Jane Petrowski and David Baird identify a shared commitment to the mission of the CEL and the presence of 'collaborative personalities' as important elements of the success of the initiative. Several early actions meant to foster the formation of strong bonds among team members, including attending a conference together and holding group meetings, actively helped these elements along. Based on the CEL experience the authors conclude that true innovation requires group participation and an open atmosphere of creativity, freedom, and fun. ${ }^{4}$

Martha K. Heyman finds that in addition to trust, good partnerships are built on equal relationships, including equitable risk, equitable responsibility, and equitable contributions from both parties. Trust requires that the participants demonstrate competence or relevant knowledge, a focus on fixing problems (not blaming people), a willingness to acknowledge mistakes and limitations, a cooperative spirit, and a willingness to give and receive help. To become a truly integrated peer in a collaboration, the content expert must recognize and clearly articulate what he or she brings to the table, namely expert knowledge of information resources, skill in conceptual analysis, ability to structure and organize content, and ability to synthesize information. Without this clarity, the skills of the content expert may be underestimated 
or undervalued, resulting in an artificially asymmetrical, rather than equal, relationship between collaborating partners. Learning IT terminology and understanding its tools and techniques can facilitate communication with IT collaborators. Credibility as a team member must be built over time by contributing to successful projects. ${ }^{5}$

Janet L.Cowen and Jerry Edson identify the missions of library and IT units as having several points in common: commitment to the organization's strategic objectives and the use of information to support those goals; stewardship of the organization's information assets; providing users convenient, secure, and confidential access to information; and meeting user expectations. Likewise, the two groups share several problems-inadequate budgets, insufficient staffing levels and staff expertise, lack of high-level administrative support, and high user expectations - that consistently require technology upgrades and innovation in response. Cowen and Edson suggest that librarians can improve library/IT partnerships by aligning library projects with specific organizational goals so that they also become de facto IT goals, by taking an interest in IT projects that do not affect the library directly, and by attending meetings about technology even if the language used is unfamiliar to them. Both sides of the partnership can improve collaboration by recognizing differences in professional culture while respecting differences in areas of expertise and responsibility. ${ }^{6}$

Mark Cain observes that despite differences in professional culture it is essential for libraries, as one of the largest campus consumers of IT services, to maintain good relationships with IT departments. These differences are the result of professional history: Libraries are long established and steeped in traditions of both thought and practice. IT departments are newer, less welldefined, and respond rapidly to changing environments. Currently, distinct sets of credentials, jargons, and standards reinforce these differences, yet the two cultures are moving ever closer together. As they become increasingly interdependent, their common goals will matter more than their differences. ${ }^{7}$

At Hamilton College, library and IT collaborators began their partnership by participating in a two-day, facilitated retreat meant to help them reduce misunderstandings and see beyond their stereotypes of one another in order to find common ground. ${ }^{8}$ Similarly, St. Cloud State University's staffers initiated the Learning Resources and Technology Services (LR\&TS) group with a joint library/IT retreat but in support of a different sort of collaboration built on the librarian liaison model. ${ }^{9}$ Librarians and technologists paired up in teams as co-liaisons in order to provide a broader range of information services to academic departments. While initially the co-liaison concept appears most applicable to librarians already participating in liaison relationships, a similar model could be applied for archivists and others engaged in educating academic departments about electronic records creation, retention, and deposit, especially in support of institutional repository development. 
When developing a partnership with campus IT, librarians at Indiana University-Bloomington found the crafting of a memorandum of understanding (MOU) to be a valuable process for setting expectations and fostering fairness between participants. An MOU is a document that clearly defines agreements between collaboration partners about goals, principles, responsibilities, governance, funding, and assessments. If properly developed, an MOU helps to manage the engagement between departments, ensures the commitment of promised resources, allows flexibility, engenders confidence in the partnership, and stands as a model for future collaborations. ${ }^{10}$

Liz Orna separates the parties necessary for building 'information products,' which she defines as consisting of both content (collections) and container (storage and delivery mechanisms) into three groups: the library professionals, the IT professionals, and the information designers. The latter, who are responsible for interface design and integration, are typically hired from outside of the organization or exist within the organization but very separate from the other two professional groups. Orna identifies three pitfalls of collaboration between these groups: (1) the participants have a limited view of both information products and their respective roles (especially between library professionals and information designers), (2) they have a limited understanding of one another's skills and how they are applied, and (3) top-level administration has a limited understanding of all three groups as well as of information products. The last of these is the most serious and difficult problem to overcome. The result is that administrators not only put too much responsibility for initiatives on IT professionals and not enough on library professionals but also are not at all sure how to select or manage information designers. As a solution Orna proposes engaging in a type of communication based on observation and internal and external 'sense-making' that allows partners to better understand their own and each others' full range of skills. Once individuals learn to engage in this sort of communication, others in the organization will better understand and appreciate their respective contributions to a collective effort. ${ }^{11}$

\section{ANALYSIS}

The general impediments to collaboration between content experts and technology experts are persistent and well understood. Differing professsional cultures, customs, and training; lack of respect or understanding of one another's skills; limited abilities to envision change; and lack of support from or mismanagement by higher-ups are of few of the often cited reason for the difficulty. The suggested remedies tend to confirm Rosabeth M. Kanter's 1994 findings about the fundamentals of successful alliances, which are echoed in nearly all the literature reviewed here (if not always explicitly cited): true collaborations are mutually beneficial, open opportunities for 
continued relationships, and involve complex interpersonal connections. They must be based on trust, mutual understanding, and respect for one another's skills and professions. ${ }^{12}$ Additionally, some researchers stress the importance of fundamental fairness in collaborative partnerships:

assuming shared risk, taking equal responsibility for outcomes, and making comparable contributions in resources and expertise.

Although achieving the ideal conditions for collaboration sounds like a daunting task, successful models for working together do exist and typically incorporate deliberate efforts to start out on the right path. Collaborators participate in activities and exercises intended to encourage teamwork, create group identity, nurture trust, foster mutual understanding, eliminate stereotypes, encourage creativity, and develop a shared sense purpose. Aligning projects with broad goals of the institution and formally establishing clear expectations can make it easier to initiate partnerships, gain the support of upper-level administrators, and sustain a cooperative spirit long term.

The literature about collaborations between content experts and technology experts is sparse and almost exclusively refers to libraries and libraryians, not archives and archivists, presumably because the problem has been better defined in the library context. While most of the reviewed research is applicable to both of these closely allied professions, if not always equally so, an effort should be made to better understand the particular requirements and problems of archives/IT relationships in future research. With some effort, facets of these problems can be found elsewhere in the professional literature and in discussions that take place within the archives community. In Sonia Yaco's 2008 assessment of Encoded Archival Description (EAD) implementations, she observes that one of the barriers to EAD implementation is a lack of a 'culture of collaboration' among archivists who, from necessity, have cultivated independence and self-reliance as means of getting things done when faced with limited staff and a lack of institutional support. Some EAD implementers learned EAD in isolation and began encoding finding aids but ultimately lacked the technological expertise necessary to deliver them online. Archivists in need found little support from campus IT units, which Yaco attributes to a general lack of understanding of the mission of the library and archives. ${ }^{13}$

Participants in our discussion session "Working Together: Campus Digital Partnerships" reported that they often had to find creative, but not always efficient or sustainable, ways of working around IT in order to get technology-based projects done. They felt working with IT was not an option, usually because they had no formal relationship with IT and no means of establishing one. For example, one creative, low technology threshold solution discussed in our session for mounting a digital project was using free Internet photo hosting services. For the archivist in search of a technology solution, this sort of 'work-around' gives immediate results but creates a host of long-term problems that result from using for archival work a service 
designed for an entirely different purpose. The nonsupport of standardized metadata, inadequate options for expressing the relationships between objects, and reliance on vendors with whom no formal relationship exists are just a few of the difficulties archivists encounter when they seek technology solutions that do not require IT coordination or support.

\section{CONCLUSION}

While there are successful library/IT partnerships we can look to for examples of how to work together, Yaco found the collaboration situation between archivists and technologists little improved over the intervening years since Lippincott's reports on the CNI's "Working Together" workshops. Our conference session participants confirmed that no matter how much they wish things were different, true collaboration with IT currently lies outside their grasp. Clearly, there is still much work to be done to understand how the collaboration problems between content experts and technology experts specifically affect the work of archivists. A partial explanation may be that archivists, to an even greater extent than librarians, are at a disadvantage when it comes to enlisting the help of IT departments, because archives typically represent an even smaller, less well understood unit than the library as a whole.

Despite the potential difficulties in obtaining assistance, it is clear that content experts in general will need help from others-going it alone does not work for either archivists or librarians anymore. This is especially true as we take on ambitious, whole-institution projects, such as developing institutional repositories, in an environment of rapidly expanding technological innovation and contracting resources. Failure to collaborate may mean our eventual marginalization or exclusion from important projects, resulting in missed opportunities to contribute where our professional skills are most needed. Becoming good collaborators will involve gaining a realistic understanding of our current and potential impacts, the financial and professional resources we will require to do our work, the skills we can contribute, and what we will need from others in order to do more.

That libraries, archives, and IT departments are different sorts of organizations with different histories, cultures, priorities, and standards seems obvious. That we also share a common academic culture, orientation toward service, and educational mission should also be obvious. Yet these two sets of facts bear repeating, as they are part problem and part solution to our reluctance to work together. Both our similarities and differences can become the roots of contention as we feel the need to protect our professional territory or the ultimate sources of strength as we recognize how interdependent we truly are. Communication is key, but not the only key, and does little on its own to advance our work. Successful collaborations require truly 
working together, solving problems together, and creating something new together-these are just as essential to real collaboration as understanding how we are alike and how we are different.

\section{NOTES}

1. Joan K. Lippincott, "Working Together: Building Collaboration between Librarians and Information Technologists," Information Technology and Libraries 17 (1999): 83-85.

2. Joan K. Lippincott, "Working Together: A Collaboration Among Archivists, Records Managers, and Information Technologists," ARL Newsletter 202 (1998): 7-9.

3. Merri Beth Lavagnino, "Librarians and Information Technologists: More Alike than Different? Interviews with CIOs," Library Hi Tech 17 (1999): 117-120.

4. Mary Jane Petrowski and David Baird, "Building a Successful Collaboration," College \& Research Libraries News 61, no. 11 (December 2000): 1004-1005.

5. Martha K. Heyman, "Building Successful Relationships with IT Professionals," Information Outlook 5, no. 4: 35-41.

6. Janet L. Cowen and Jerry Edson, "Best Practice in Library/Information Technology Collaboration," Journal of Hospital Librarianship 2, no. 4 (December 2002): 3-13. doi:10.1300/J186v02n04 01.

7. Mark Cain, "The Two Cultures? Librarians and Technologists," Journal of Academic Librarianship 29, no. 3 (May 2003): 177-181.

8. Randall L. Ericson, "Living and Thriving with Library/ITS Collaboration," College \& Research Libraries News 65, no. 9 (October 2004): 513.

9. Susan H. Motin and Pamela M. Salela, "A Liaison Model for Integrating the Library, IT, Web, and Marketing Teams," Technical Services Quarterly 24, no. 1 (2006): 1-15. doi:10.1300/J124v24n01-01.

10. Carolyn M. Walters and Elizabeth A. Van Gordon, "Get it in Writing: MOUs and Library/IT Partnerships,” Reference Services Review 35, no. 3 (2007): 389-392.

11. Liz Orna, "Collaboration between Library and Information Science and Information Design Disciplines. On What? Why? Potential Benefits?" Information Research 12, no. 4 (October 2007): 1-32.

12. Rosabeth M. Kanter, "Collaborative Advantage: The Art of Alliances," Harvard Business Review 312 72, no. 4 (1994): 96-108.

13. Sonia Yaco, "It's Complicated: Barriers to EAD Implementation," American Archivist 71, no. 2 (2008): 456-475.

\section{ABOUT THE CONTRIBUTOR}

Eleta Exline, MS LIS, is Digital Collections Librarian at The University Library, University of New Hampshire in Durham, New Hampshire. 